\title{
EXTRACORPOREAL CIRCULATION CAN INDUCE HYPOTENSION BY BOTH BLOOD-MATERIAL CONTACT AND PUMP-INDUCED PLATELET AGGREGATION
}

Piet Borgdorff, PhD

Gerard van den Bos, MD, PhD

Geert Jan Tangelder, MD, PhD
Objective: Use of extracorporeal systems in cardiopulmonary bypass and dialysis induces vascular reactions, which can lead to hypotension and lung edema.

Methods: To study the contribution of blood-material contact and use of a roller pump, as well as prevention of their adverse effects, we perfused a rat hind leg with a tube connecting a carotid and a femoral artery.

Results: Autoperfusion of an uncoated tube caused a fall of aortic pressure and femoral resistance to $66 \% \pm 16 \%$ and $76 \% \pm 15 \%$, respectively, of their initial values within 2 hours, whereas in control animals without a shunt, these variables hardly changed (to $94 \% \pm 2.8 \%$ and $99 \% \pm 2.8 \%$, respectively). Lung water content became significantly higher than that found in control animals $(79.4 \% \pm 1.50 \%$ versus $77.0 \% \pm 1.67 \%)$. If we coated the tube with albumin, these changes were largely prevented. When the coated tube was placed in a roller pump, aortic pressure and femoral resistance immediately fell to $79 \% \pm 17.2 \%$ and $63 \% \pm 13.5 \%$, respectively, whereas lung water content did not increase. The vasodilation was caused by platelet aggregation and could be prevented with aurintricarboxylic acid, which inhibits shear-induced platelet aggregation by blocking the binding of von Willebrand factor to platelet glycoprotein Ib receptors.

Conclusions: Extracorporeal circulation may induce hypotension and lung edema by means of blood-material contact. Hypotension can be prevented by coating the system with albumin but can still result from pump-induced platelet aggregation. (J Thorac Cardiovasc Surg 2000;120:12-9)
U se of extracorporeal systems in cardiopulmonary bypass and dialysis may induce serious vascular derangements, such as hypotension and edema. ${ }^{1-4}$ This may be an effect of blood-material contact activating the complement system, the contact system, and blood platelets, with release of agents that lead to vasodilation and vascular leakage, such as bradykinin, ${ }^{5}$ histamine, ${ }^{5}$ and serotonin. ${ }^{5-7}$ Coating the foreign material with

From Laboratory for Physiology, Institute for Cardiovascular Research Vrije Universiteit (ICaR-VU), Amsterdam, The Netherlands.

Received for publication Sept 22, 1999; revisions requested Dec 1, 1999; revisions received Dec 27, 1999; accepted for publication Dec 29, 1999.

Address for reprints: P. Borgdorff, PhD, Laboratory for Physiology, Vrije Universiteit, Van der Boechorststraat 7, 1081 BT Amsterdam, The Netherlands (E-mail: p.borgdorff.physiol@med.vu.nl).

Copyright $\odot 2000$ by The American Association for Thoracic Surgery $0022-5223 / 2000 \$ 12.00+0 \quad \mathbf{1 2 / 1 / 1 0 5 4 5 4}$

doi:10.1067/mtc.2000.105454 heparin is thought to reduce these effects. Heparinbonded systems indeed improve clinical outcomes, ${ }^{8}$ by preventing complement and contact activation, ${ }^{9,10}$ and platelet adhesion. ${ }^{11}$ They do not prevent platelet activation, however. ${ }^{12,13}$ This indicates that platelets might also be activated by other factors than blood-material contact and in this way cause vascular problems. In a recent study with rat and human blood, we demonstrated that platelets in albumin-coated extracorporeal systems can be activated by elevated shear stress caused by the pump. ${ }^{14}$ The goal of the present study was to separate the effects of pump and blood-material contact and to investigate whether both can induce hypotension and edema. We also studied whether these effects can be prevented by coating the system with albumin and by blocking pump-induced platelet aggregation. Albumin was used instead of heparin to avoid possible direct effects of surface-bound heparin on platelets. Moreover, it has been reported to be as effective as heparin coating in preventing platelet aggregation and activation caused by blood-material contact. ${ }^{11,15}$ 


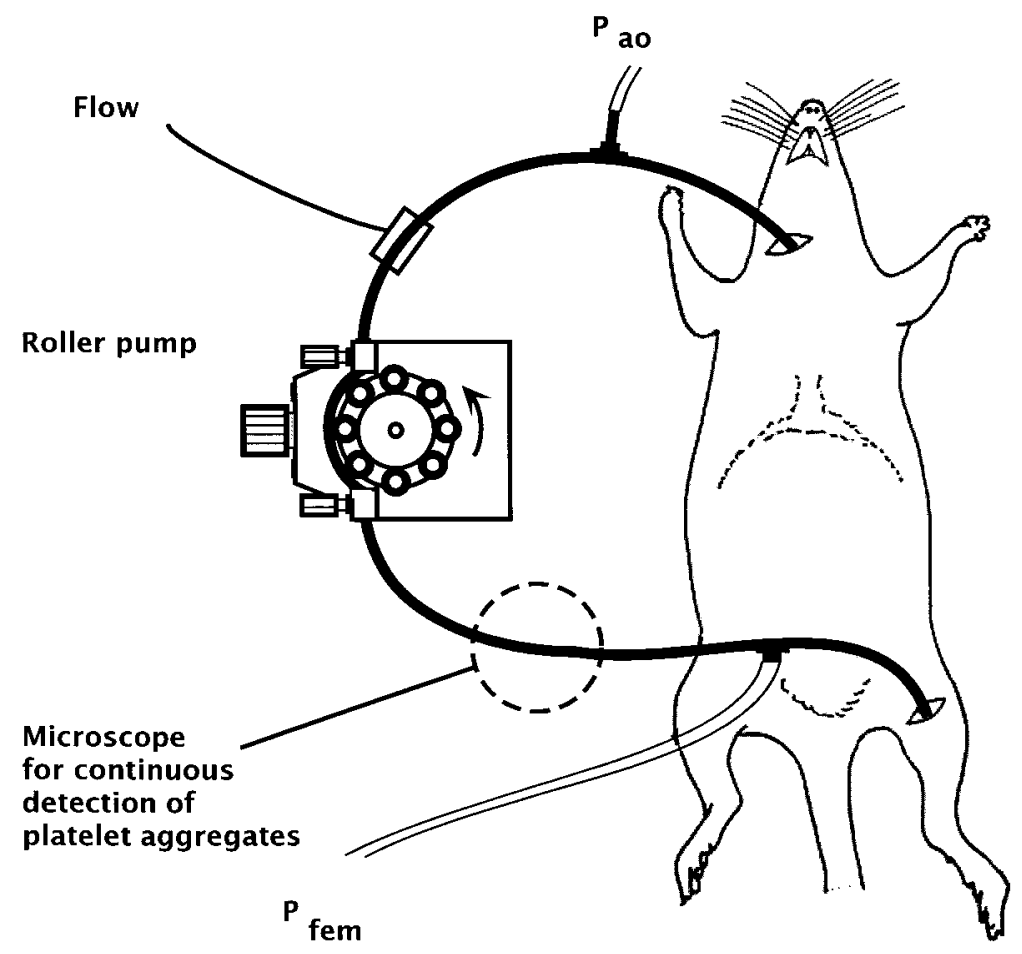

Fig 1. Extracorporeal shunt between carotid and femoral artery in the rat. Aortic $\left(P_{a o}\right)$ and femoral $\left(P_{f e m}\right)$ pressures, flow, and platelet aggregation were measured at the positions indicated. During autoperfusion, the tube was not compressed. By tightening the rollers and starting the pump, spontaneous flow could simply be replaced by pump flow.

\section{Methods}

Male Wistar rats (335-410 g) were anesthetized with an intramuscular bolus of ketamine (10\%, $60 \mathrm{mg} / \mathrm{kg}$; Kombivet) and a subsequent intraperitoneal injection of pentobarbital (Nembutal, $35 \mathrm{mg} / \mathrm{kg}$ ). Thereafter, pentobarbital was continuously infused at 10 to $14 \mathrm{mg} / \mathrm{kg}$ per hour. After tracheotomy, the animals were ventilated with a mixture of room air and oxygen (3:1) at 90 breaths/min. Tidal volume was adjusted so that a capnometer (Datex Normocap D-102, Helsinki, Finland) indicated an end-expiratory carbon dioxide content of $5 \%$, corresponding with an arterial $\mathrm{PCO}_{2}$ of approximately $40 \mathrm{~mm} \mathrm{Hg}$. Mean arterial $\mathrm{pH}$ and $\mathrm{PO}_{2}$ ranged from 7.32 to 7.45 and from 76 to $132 \mathrm{~mm} \mathrm{Hg}$, respectively. Body temperature was kept at $37.5^{\circ} \mathrm{C}$ by using a servo-controlled heating device. All handling of the animals was in compliance with the "Guide for the Care and Use of Laboratory Animals" (National Institutes of Health publication No. 85-23, revised 1985).

The rats were heparinized intravenously with $800 \mathrm{IU} / \mathrm{kg}$ (Leo Pharmaceutical Products BV, Weesp, The Netherlands). After cannulation of the central part of a carotid (20-gauge cannula) and distal part of the left femoral artery (22-gauge cannula), the cannulas were interconnected with new medical grade polyvinyl chloride tubing (Fig 1). In the autoperfusion experiments this tube $(1.5 \mathrm{~mm}$ inner diameter $)$ was $30 \mathrm{~cm}$ long and filled with heparinized saline solution. During the connection procedure, flow to the leg was interrupted for 2 to 3 minutes only. A warming lamp above the animal kept the blood in the tube at $37^{\circ} \mathrm{C} \pm 1^{\circ} \mathrm{C}$. In the pump experiments the tube had a length of $45 \mathrm{~cm}$, and part of the tube was loosely positioned in the roller pump. If the tube in the pump was not compressed, blood flowed spontaneously $(2-4 \mathrm{~mL} / \mathrm{min})$ as a result of the pressure difference between the central carotid and distal femoral artery. For transition to pump flow, the tube was gradually compressed until flow stopped, and the pump was then started and set to the spontaneous flow immediately before institution of pump flow.

The whole system was either coated with albumin or not coated. The method of coating has been described previously. ${ }^{16}$ Tests with radioactively labeled albumin showed that the coating consisted of one to two monolayers and was stable during at least 4 hours of blood perfusion.

Flow in the tubing was measured with a perivascular flow probe (1RB; Transonic Systems Inc, Ithaca, NY). The measurement was calibrated in vitro by using timed collection of blood at $37^{\circ} \mathrm{C}$. Aortic and femoral pressures were measured with Statham P23 Db pressure transducers (Viggo Spectramed, Inc, Critical Care Division, Oxnard, Calif) by using stainless steel $\mathrm{T}$ pieces in the shunt at approximately 3 $\mathrm{cm}$ from the carotid cannula and just before the femoral can- 
nula. Femoral resistance was calculated from the ratio of femoral pressure and flow.

Measurement of platelet behavior. In the pump experiments possible platelet aggregation in the tube was continuously measured with a photometric device by using the fact that light transmission through flowing blood increases during passage of platelet aggregates. ${ }^{17}$ Distal to the pump (Fig 1 ), the tube was serially connected to a $12-\mathrm{mm}$ long albumincoated glass capillary (inner diameter $0.6 \mathrm{~mm}$ ) on the stage of a microscope. The image of this capillary was projected onto an array of photosensitive cells, and passage of aggregates was indicated by short-lasting voltage peaks. For quantitation of aggregation, the signals were converted to uniform spikes with a spike processor and subsequently counted over fixed periods. The result was related to the value found after injection of $2 \mathrm{ng}$ of adenosine diphosphate into the tube. This dose was dissolved in $20 \mu \mathrm{L}$ of saline solution and elicited, when injected within half a second, strong aggregation that did not impede flow.

For platelet counting and visual inspection of aggregates, blood $(0.1 \mathrm{~mL})$ was withdrawn from the distal T piece and added to $0.15 \mathrm{~mL}$ of ethylenediamine tetraacetic acid solution (3.6 $\mathrm{mg} / \mathrm{mL}$ saline solution), resulting in a final concentration of $6.6 \mathrm{mmol} / \mathrm{L}$ to stabilize the aggregates. Then $0.02 \mathrm{~mL}$ was added to $2 \mathrm{~mL}$ of Thromboplus solution and inspected in a Bürker counting chamber under phase-contrast microscopy (400×). Periodic comparison confirmed the results obtained with the continuous aggregometer and indicated that with that meter only aggregates were detected that consisted of 4 or more platelets. Platelets were counted with a Coulter counter (model ZF; Coulter Electronics, Inc, Hialeah, Fla), and the counts were corrected for hematocrit. For measurement of hemolysis, $1 \mathrm{~mL}$ of arterial blood was withdrawn before and after the experiment, and free hemoglobin in plasma was determined by using a colorimetric method at $600 \mathrm{~nm}$ (Sigma Chemical Company, St Louis, Mo; procedure No. 527).

Measurement of tissue water content. Edema formation in the hind legs and lungs was studied by calculating the percentage of tissue water from the difference between wet and dry weight. At the end of the experiment, approximately $1 \mathrm{~g}$ of gastrocnemius muscle was removed and freed of blood by gentle squeezing of the muscle with a paper tissue. The lungs were inflated in situ, tied off, and then removed. Both tissues were weighed, dried overnight at $60^{\circ} \mathrm{C}$, and weighed again. Control values of lung water content were derived from animals that were killed immediately after induction of anesthesia; their hearts were used for other experiments.

Aurintricarboxylic acid. A trisodium salt of aurintricarboxylic acid (ATA; Aldrich Chemical Company, Bornem, Belgium) was dissolved $(30 \mathrm{mg} / \mathrm{mL})$ in phosphate buffer $(\mathrm{pH}$ =7.4). A bolus of $35 \mathrm{mg} / \mathrm{kg}$ was infused intravenously within 10 minutes in rats that had not been exposed to pump perfusion before. In a previous study ${ }^{17}$ this dose effectively inhibited platelet aggregation in rats in which a mean shear stress of 231 dynes $/ \mathrm{cm}^{2}$ was generated by partial occlusion of a tube between the carotid and femoral arteries.
Statistics. Values in the text and legends are expressed as means $\pm \mathrm{SD}$, and those in the figures are expressed as means \pm SEM. Time series data (Figs 2 and 3) were analyzed by using 2-way analysis of variance for repeated measurements. If the $P$ value was smaller than .05 , posttests for comparison between conditions at different times were performed with the Bonferroni multiple comparison procedure. Water content data were analyzed with the Kruskal-Wallis test and posttested with the Dunn multiple comparison test. For comparison between left and right leg data, the Wilcoxon matched pairs test was used.

\section{Results}

Hypotensive effect of blood-material contact. In animals not connected to an extracorporeal circuit (group $1, \mathrm{n}=8$ ), femoral resistance remained at baseline level for 2 hours (Fig 2, squares), whereas aortic pressure showed a small decrease to $94 \% \pm 2.8 \%$ of its initial value $(P=.001)$. In animals with an uncoated tube between the carotid and femoral arteries (group 2, $\mathrm{n}=9$ ), femoral resistance and aortic pressure decreased within 2 hours to $76 \% \pm 15 \%$ and $66 \% \pm 16.2 \%$ of their initial values, respectively (Fig 2, diamonds). Coating the tube with albumin (group 3, n = 9) largely prevented this: femoral resistance dropped to $96 \% \pm 13.8 \%$ only and aortic pressure to $87 \% \pm 9 \%$ (Fig 2, circles). Heart rate $(381 \pm 45$ beats $/ \mathrm{min})$ did not change significantly in any of the 3 groups.

Hypotensive effect of the pump. Start of pump perfusion in experiments with an albumin-coated tube (group $4, \mathrm{n}=7$ ) caused an immediate and significant fall of femoral resistance and aortic pressure to $63 \% \pm$ $13.5 \%$ and $79 \% \pm 17.2 \%$ of their initial values, respectively (Fig 3, diamonds). Thereafter, femoral resistance slowly increased and stabilized at about $70 \%$ of its control value. Aortic pressure recovered within 20 minutes to about $92 \%$ and then slightly decreased with a similar amount as occurred in the absence of a pump (Fig 3, circles). Pumping had no significant effect on heart rate.

The decrease of femoral resistance by pump perfusion must have been caused by vasodilation because blood viscosity remained unaltered as judged from hematocrit values: $49 \% \pm 2.6 \%$ before and $50 \% \pm 2.6 \%$ after 2 hours of pumping.

Comparison of the hypotensive effects. The decline of peripheral resistance and aortic pressure was gradual when caused by blood-material contact but steep when caused by pump perfusion. During the first 40 minutes, peripheral resistance was significantly $(P=.001)$ lower during pump perfusion than during autoperfusion. For aortic pressure, the difference was significant $(P=$ $.006)$ at 5 minutes and again at 120 minutes. 

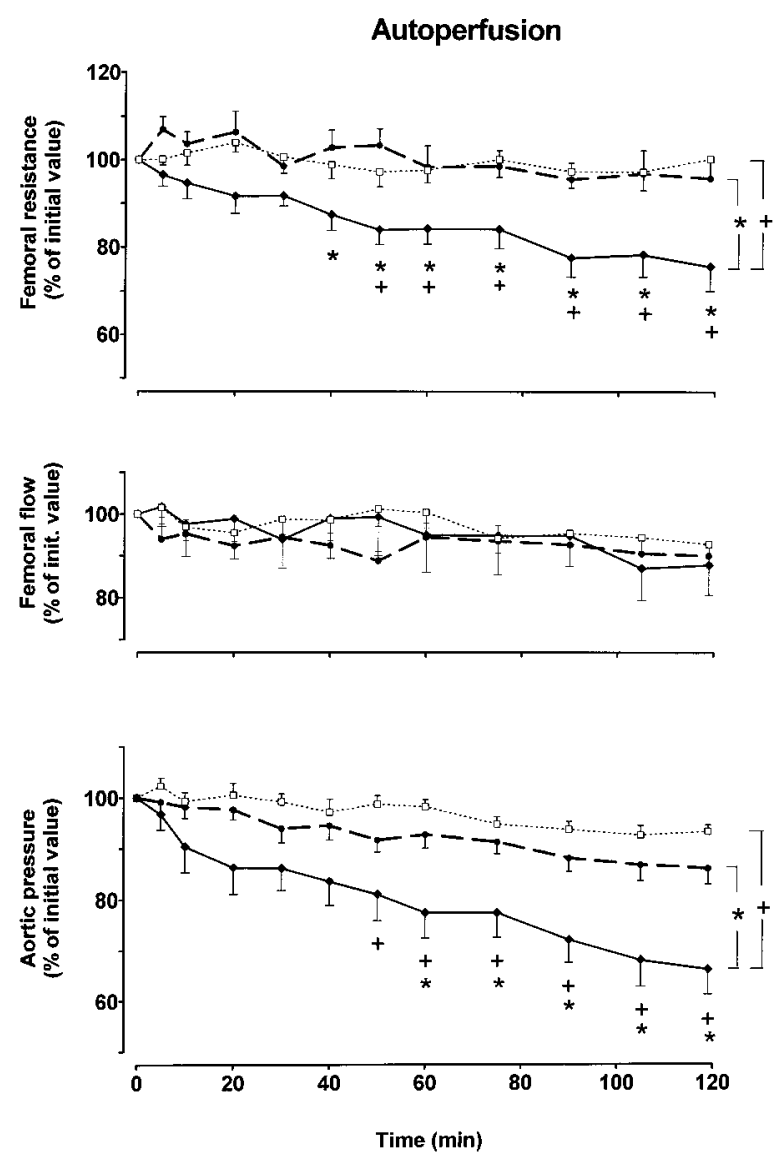

Fig 2. Time course of cardiovascular variables (means \pm $\mathrm{SEM}$ ) during autoperfusion (no tube $[\mathrm{n}=8]$ : open squares, dotted line; uncoated tube $[\mathrm{n}=9]$ : filled diamonds, solid line; coated tube $[\mathrm{n}=9]$ ]: filled circles, dashed line). Initial values (means \pm SD at time 0 ) were as follows: femoral resistance of $60 \pm 9.3$ (open squares), $71 \pm 13$ (filled diamonds), and $68 \pm$ $10.3 \mathrm{~mm} \mathrm{Hg} \cdot \min \cdot \mathrm{mL}^{-1}$ (filled circles); femoral flow of 2.38 \pm 0.32 (open squares), $2.03 \pm 0.43$ (filled diamonds), and $2.08 \pm 0.44 \mathrm{~mL} / \mathrm{min}$ (filled circles); and aortic pressure of 146 \pm 7.6 (open squares), $135 \pm 10.5$ (filled diamonds), and 135 $\pm 13.5 \mathrm{~mm} \mathrm{Hg}$ (filled circles). Plus signs and asterisks indicate significant difference for uncoated (filled diamonds) versus control (open squares) and for uncoated (filled diamonds) versus coated (filled circles), respectively.

Edema formation. The upper panel of Fig 4 shows that water content of the lungs was higher $(P=.02)$ after 2 hours of autoperfusion through an uncoated tube (group 2, $\mathrm{n}=8,79.4 \% \pm 1.50 \%$ ) than without a tube (group 6, $\mathrm{n}=10,77.0 \% \pm 1.67 \%$ ). By contrast, use of a pump with a coated tube (group $4, n=4$ ) did not seem to increase lung water content. The lower panel of Fig 4 shows that the water content of the gastrocnemius muscle of the left leg did not exceed that of the right

\section{Pump Perfusion}
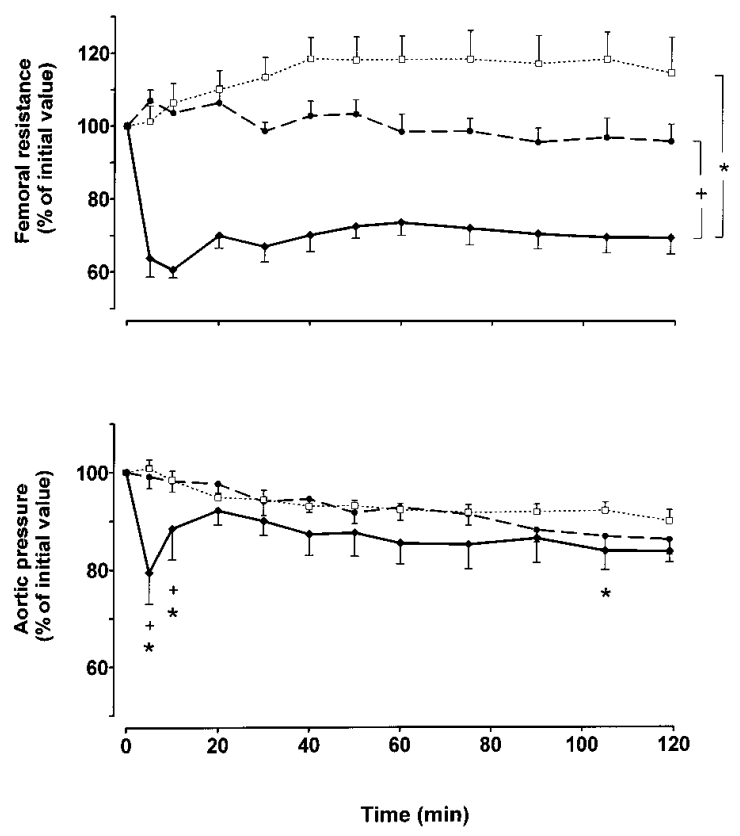

Fig 3. Time course of cardiovascular variables (means \pm SEM) after onset of pump perfusion in an albumin-coated tube without (filled diamond, solid line, $\mathrm{n}=7$ ) and with (open squares, dotted line, $\mathrm{n}=7$ ) ATA. Pump flow was set equal to spontaneous flow. Results with autoperfusion in the coated tube (filled circles, dashed line, $\mathrm{n}=9$ ) are the same as in Fig 2 and shown for comparison. Initial values (means \pm SD at time 0) were as follows: femoral resistance of $71 \pm 13.5$ (filled diamonds), $123 \pm 19.3$ (open squares), and $68 \pm 10.3$ $\mathrm{mm} \mathrm{Hg} \cdot \min \cdot \mathrm{mL}^{-1}$ (filled circles); and aortic pressure of $124 \pm 9.8$ (filled diamonds), $132 \pm 15.3$ (open squares), and $135 \pm 13.5 \mathrm{~mm} \mathrm{Hg}$ (filled circles). Plus signs indicate significant difference between pump without ATA (filled diamonds) and autoperfusion (filled circles). Asterisks indicate significant difference between pump without ATA (filled diamonds) and pump with ATA (open squares). For femoral resistance, the differences between pumping without ATA and the other two conditions were significant at all time points.

noncannulated leg whether it was autoperfused with an uncoated tube or pump-perfused with a coated tube. The values were actually always somewhat lower in the left than in the right leg (13 pairs, $P=.001$ ).

Platelet aggregation during pumping. Since the start of pump perfusion had an immediate vasodilatory and hypotensive effect, we evaluated whether this could have been caused by activation of platelets. As long as the coated tube was not compressed and blood flowed freely from the carotid to the femoral artery, no platelet aggregation was observed (Fig 5, left panel). However, the start of the pump instantaneously elicited platelet 

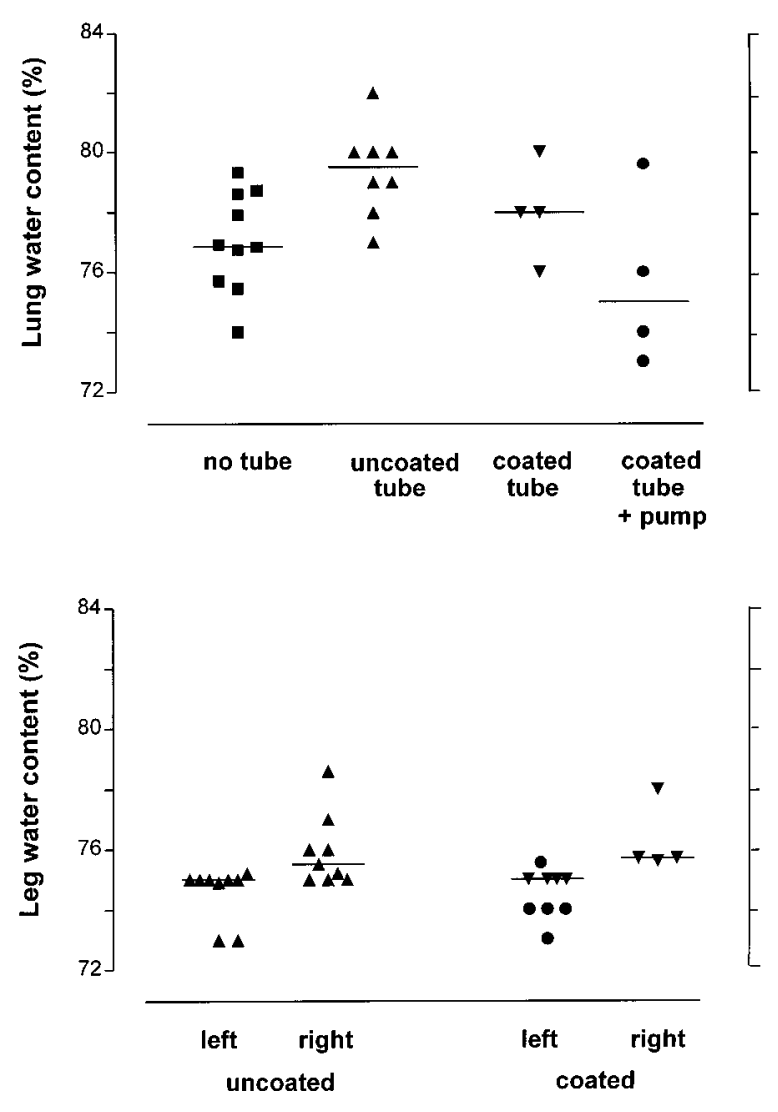

Fig 4. Water content in lungs (upper panel) and gastrocnemius muscle of the left and right leg (lower panel) after 2 hours of perfusion with an uncoated or an albumin-coated tube. The group with a coated tube consists of experiments with tube only (filled triangles) and experiments with tube plus pump (filled circles). Presented are the individual values and the median. The difference in lung water content between the uncoated tube and no tube is significant $(P=.02)$. In the legs the water content is somewhat lower $(P=.001)$ in the tube-perfused left leg than in the right leg.

aggregation that diminished after 2 to 3 minutes but remained present at a lower level for the duration of pump perfusion. The mean aggregate formation during the first 10 minutes is indicated in Fig 6 (diamonds).

Fig 5 also illustrates the effect of pump perfusion on femoral pressure. Because the pump was instantaneously adjusted to make flow equal to the mean spontaneous flow, the fall of femoral pressure indicated a fall of femoral vascular resistance.

Return from pump perfusion to autoperfusion stopped the aggregation, but femoral resistance did not recover. Restart of the pump again elicited some platelet aggregation, but this did not now influence femoral resistance. The disappearance of platelet aggregation at the stop of pump perfusion indicates that the aggregates did not recirculate. They probably disaggregated because the number of platelets after 2 hours of pumping was not decreased: $1090 \pm 179$ after versus $1054 \pm 148 \times 10^{9} / \mathrm{L}$ before pumping $(\mathrm{n}=7)$.

Also in the autoperfusion experiments, platelet count remained at its initial level. With an uncoated tube, the counts before and after 2 hours of perfusion were 890 \pm 180 and $872 \pm 183 \times 10^{9} / \mathrm{L}$, respectively $(\mathrm{n}=9)$. With a coated tube, these numbers were $772 \pm 210$ and 774 $\pm 213 \times 10^{9} / \mathrm{L}$, respectively $(\mathrm{n}=9)$.

Inhibition of pump-induced platelet aggregation. To further validate the role of platelet aggregation in eliciting the vasodilation in the leg, another group of rats (group $5, \mathrm{n}=7$ ) received ATA, a specific inhibitor of shear stress-induced platelet aggregation. Fig 5 (right panel) shows that the start of pump perfusion after administration of ATA did not evoke aggregation of platelets and did not lower femoral resistance, as judged from the unchanged femoral pressure and flow. Instead, femoral resistance slowly increased to an average of about $118 \%$ of its control level (Fig 3, squares). Fig 3 also shows that ATA prevented the immediate fall of aortic pressure. Its mean values were similar to or even higher than those found in the experiments with coated tubes in which no pump was used. The absence of pump-induced platelet aggregation after administration of ATA is quantitatively shown in Fig 6 (squares). Platelet aggregation reappeared when, after 2 to 2.5 hours, the effect of ATA waned.

A contribution of pump-induced hemolysis to the aggregation of platelets seems unlikely because the mean change in plasma-free hemoglobin after 2 hours of pump perfusion was only an increase of $2.38 \pm 4.97$ $\mathrm{mg} / \mathrm{dL}(\mathrm{n}=7)$. This value is small compared with the values of 26 to $82 \mathrm{mg} / \mathrm{dL}$ found in clinical cardiopulmonary bypass studies. ${ }^{18,19}$

\section{Discussion}

Perfusion of the rat hind leg through an uncoated tube between the carotid and femoral arteries caused a slow but pronounced fall in femoral resistance and aortic pressure and increased the water content of the lungs. Coating the tube with albumin largely prevented these effects, but femoral resistance and aortic pressure fell again as soon as the coated tube was placed in a roller pump. This was accompanied by strong aggregation of platelets in the tube distal to the pump and could be prevented by inhibiting platelet aggregation with a substance that blocked the binding of von Willebrand factor to the platelet glycoprotein Ib receptors.

Although during cardiopulmonary bypass blood may 


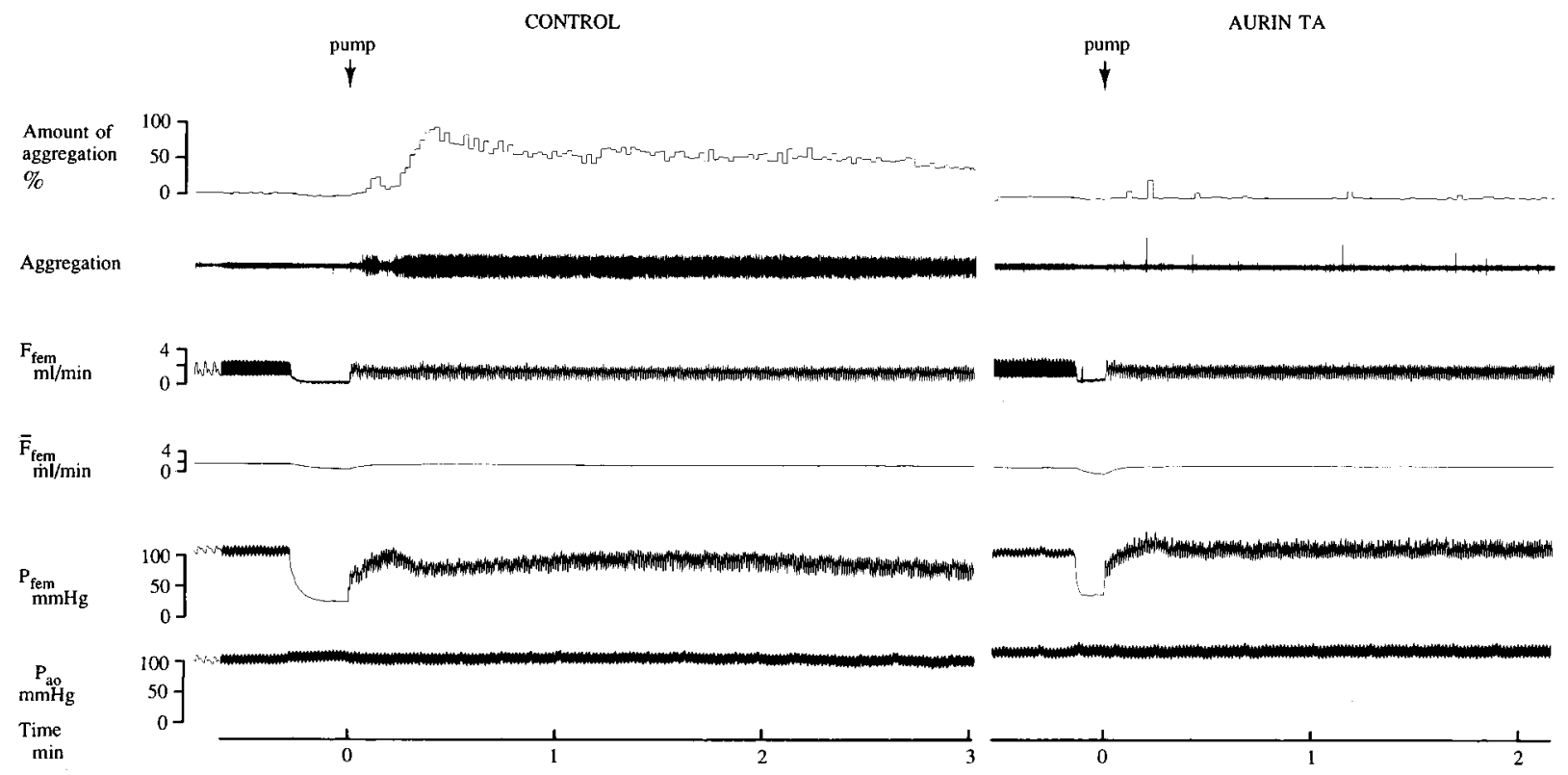

Fig 5. Effect of autoperfusion and pump perfusion in a coated tube on platelet aggregation, femoral pressure $\left(P_{f e m}\right)$ and flow $\left(F_{f e m}\right)$, and aortic pressure $\left(P_{a o}\right)$ in control animals $($ left panel $)$ and animals after administration of ATA (right panel). Pump flow was started at the place indicated by the arrow and set equal to the mean spontaneous flow. Aggregation indicates a record of raw signals from the device that measures passage of platelet aggregates in tubing. The amount of aggregation is expressed as the percentage of the value found after injection of 2 ng of adenosine diphosphate into tubing.

be activated in various ways, our study first demonstrates that the mere contact of blood with uncoated tubing is sufficient to cause a gradual fall of aortic pressure and development of lung edema. The pressure drop was at least partially the result of vasodilation because femoral resistance decreased in a similar way. Second, our study shows that the benefit of coating is reduced when a roller pump is used. Pumping resulted in an immediate fall of aortic pressure and femoral resistance. This was obviously caused by platelet aggregation because at the same time many platelet aggregates appeared in the tube section distal to the pump, and the fall of aortic pressure and femoral resistance was prevented when platelet aggregation was inhibited. A role for platelets in pump-induced vasodilation was suggested earlier by our results obtained in cats: the vasodilation caused by pump perfusion was absent after inhibition of platelet aggregation with indomethacin (INN: indometacin). ${ }^{20}$

The prevention of pump-induced platelet aggregation with ATA in the present experiments indicates that the aggregation must have been elicited by elevated shear stresses. Such aggregation is mediated by binding of large multimers of the von Willebrand factor to platelet membrane glycoprotein Ib receptors. ${ }^{21,22}$ ATA inhibits

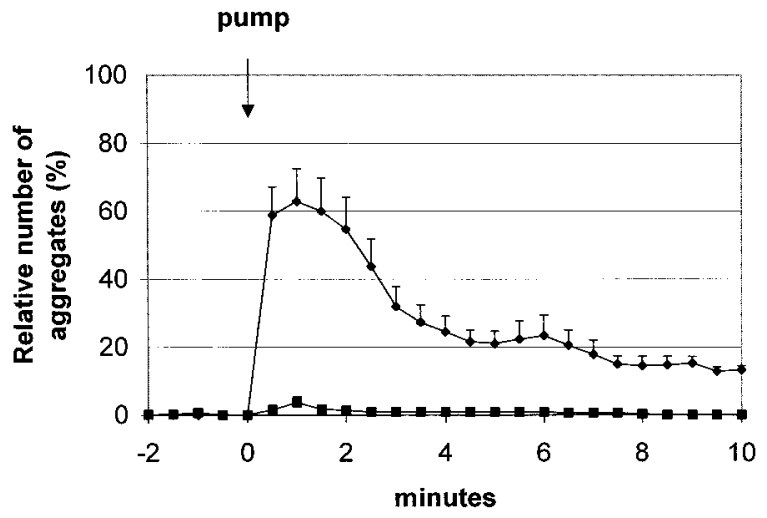

Fig 6. Increase in amount of platelet aggregation during pump perfusion in an albumin-coated tube (filled diamonds, $\mathrm{n}=7$ ) and its prevention with ATA (filled squares, $\mathrm{n}=7$ ). Values are presented as means \pm SEM.

this binding by attaching to the large von Willebrand factor multimers but not to platelets, so that their metabolic function is preserved and their reaction to adenosine diphosphate and arachidonic acid, for example, is not affected. ${ }^{21,23}$ In one experiment we corroborated the role of shear stress by blocking the von Willebrand 
factor-platelet membrane glycoprotein $\mathrm{Ib}$ interaction with VCL, a recombinant fragment of von Willebrand factor. ${ }^{24}$ Like ATA, this substance largely prevented platelet aggregation and the fall of femoral resistance and aortic pressure during pumping. Moreover, unlike ATA (Fig 3), VCL had no effect on baseline resistance. This makes it improbable that the prevention of pumpinduced vasodilation by ATA was due to elevation of baseline resistance instead of inhibition of platelet aggregation. The same is indicated by our previous experiments, in which platelet aggregation was inhibited by indomethacin, which prevented pump-induced vasodilation without affecting baseline resistance. ${ }^{20}$

Return from pump perfusion to autoperfusion stopped the passage of aggregates in the tube. This indicates that the aggregates did not recirculate. The fall of femoral resistance during platelet aggregation makes it at the same time improbable that they were permanently trapped in the microvessels of the leg. They more likely disaggregated after their arrival in the microvasculature. ${ }^{25}$ This could explain why in the present in vivo experiments the platelet count in the circulation was not lowered after 2 hours of perfusion, although it was in a recent in vitro study, ${ }^{14}$ in which the blood recirculated through a reservoir.

Our study indicates that the immediate fall of blood pressure after the start of pump perfusion is caused by platelet aggregation. We did not investigate the cause of the more gradual decline of blood pressure during autoperfusion with uncoated tubing. It is unlikely that this was caused by local limb ischemia or tissue hypoxia because tube flow to the perfused leg amounted to about $85 \%$ of native femoral artery flow (Fig 2), and collateral flow is well developed in rats. In addition, flow changes over time were similar in the autoperfused groups, irrespective of whether hypotension developed. The hypotension during autoperfusion with an uncoated tube might have resulted from activation of blood components other than platelets (eg, related to an inflammatory reaction).

Use of an uncoated circuit caused edema in the lung but not in the gastrocnemius muscle of the cannulated leg. This makes it less likely that the observed increase of lung water content was predominantly caused by a decrease of blood oncotic pressure. Moreover, the amount of hypo-oncotic priming solution in our experiments was small in relation to blood volume (2\%-3\%). Therefore, beside changes in lymph drainage, other components of the Starling equation may be responsible: changes in pulmonary capillary pressure, capillary surface area, reflection coefficient, or hydraulic conductivity. Which of these components is actually affect- ed needs further investigation. Platelets do not seem to be involved because pump perfusion caused platelet aggregation but did not seem to increase water content in legs and lungs, despite its pronounced effect on vascular tone. This is surprising given the possibility of platelets eliciting vascular leakage through release of serotonin and histamine. ${ }^{26}$

Our results can partially explain the hypotension and low systemic vascular resistance often observed in patients undergoing cardiopulmonary bypass and hemodialysis. 1,3,4 When uncoated systems are used, hypotension may ensue both from blood-material contact and from use of a pump, which is indispensable in such systems; when coated circuits are used, hypotension may still be caused by pump perfusion. In our experiments with perfusion of one femoral bed, the decrease of aortic pressure was only significant for the first 5 minutes after the start of the pump. Presumably, the pressure drop will last longer when more vascular beds are involved in the vasodilatory reaction, as in cardiopulmonary bypass. In conscious patients, as during hemodialysis, the baroreflex and other regulating systems will correct pressure changes caused by the release of a vasodilator. In anesthetized or conscious patients with autonomic dysfunction, however, these systems might not be adequate to compensate for the continuous challenge to blood pressure.

In conclusion, vasoactive mediators generated by blood-material contact can induce vasodilation and lung edema, whereas agents released from platelets activated by pumping may cause vasodilation but not edema. Albumin coating of the tubes and blocking the binding of von Willebrand factor to platelet glycoprotein $\mathrm{Ib}$ receptors prevent these unwanted side effects of extracorporeal circulation.

We thank J. P. Versluis, MSc, for the measurement of lung water content.

\section{REFERENCES}

1. Christakis GT, Fremes SE, Koch JP, et al. Determinants of low systemic vascular resistance during cardiopulmonary bypass. Ann Thorac Surg 1994;58:1040-9.

2. Butler J, Rocker GM, Westaby S. Inflammatory response to cardiopulmonary bypass. Ann Thorac Surg 1993;55:552-9.

3. Carretta R, Fabris B, Fischetti F, et al. Peripheral adrenoceptors in hypotension of hemodialyzed uremic patients. Nephron 1992; 62:429-33.

4. Maeda K, Shinzato T, Nakai S, Takai I, Kobayakawa H. Mechanism of dialysis-induced hypotension. Nagoya J Med Sci 1992;54:1-10.

5. Sakurai H, Maeda M, Murase M, Koyama T, Hayakawa M. Hemofiltration removes bradykinin generated in the priming blood in cardiopulmonary bypass during circulation. Ann Thorac Cardiovasc Surg 1998;4:59-63. 
6. Downing SW, Edmunds LH Jr. Release of vasoactive substances during cardiopulmonary bypass. Ann Thorac Surg 1992;54:123643.

7. Mylecharane EJ. Mechanisms involved in serotonin-induced vasodilatation. Blood Vessels 1990;27:116-26.

8. Aldea GS, Lilly K, Gaudiani JM, et al. Heparin-bonded circuits improve clinical outcomes in emergency coronary artery bypass grafting. J Card Surg 1997;12:389-97.

9. Gu YJ, van Oeveren W, Akkerman C, Boonstra PW, Huyzen RJ, Wildevuur CR. Heparin-coated circuits reduce the inflammatory response to cardiopulmonary bypass. Ann Thorac Surg 1993;55: 917-22.

10. te Velthuis H, Baufreton C, Jansen PG, et al. Heparin coating of extracorporeal circuits inhibits contact activation during cardiac operations. J Thorac Cardiovasc Surg 1997;114:117-22.

11. Olsson P, Lagergren H, Larsson R, Radegran K. Prevention of platelet adhesion and aggregation by a glutardialdehydestabilized heparin surface. Thromb Haemost 1977;37:27482.

12. Muehrcke DD, McCarthy PM, Kottke-Marchant K, et al. Biocompatibility of heparin-coated extracorporeal bypass circuits: a randomized, masked clinical trial. J Thorac Cardiovasc Surg 1996;112:472-83.

13. Palatianos GM, Dewanjee MK, Kapadvanjwala M, Novak S, Sfakianakis GN, Kaiser GA. Cardiopulmonary bypass with a surface-heparinized extracorporeal perfusion system. ASAIO Trans 1990;36:M476-9.

14. Borgdorff $\mathrm{P}$, van den Berg RH, Vis MA, van den Bos GC, Tangelder GJ. Pump-induced platelet aggregation in albumincoated extracorporeal systems. J Thorac Cardiovasc Surg 1999; 118:946-52.

15. Mulvihill JN, Faradji A, Oberling F, Cazenave JP. Surface passivation by human albumin of plasmapheresis circuits reduces platelet accumulation and thrombus formation: experimental and clinical studies. J Biomed Mater Res 1990;24:155-63.

16. Borgdorff P, Kok WEM, van den Bos GC. Extracorporeal circuits and autoregulation: effect of albumin coating. Am J Physiol 1992;263:H1397-401.

17. Borgdorff P, Kok WE, Vis MA, van den Bos GC. Vasodilation by shear-induced platelet aggregation in extracorporeal circuits. Am J Physiol 1994;266:H891-7.

18. Komoda T, Maeta H, Imawaki S, et al. A pulsatile cardiopulmonary bypass system that prevents negative pressure at the membrane oxygenator. ASAIO J 1993;39:936-41.

19. Murakami F, Usui A, Hiroura M, Kawamura M, Koyama T, Murase M. Clinical study of totally roller pumpless cardiopulmonary bypass system. Artif Organs 1997;21:803-7.

20. Borgdorff P, Sipkema P, Westerhof N. Pump perfusion abolishes autoregulation possibly via prostaglandin release. Am J Physiol 1988;255:H280-7.

21. Alevriadou BR, Moake JL, Turner NA, et al. Real-time analysis of shear-dependent thrombus formation and its blockade by inhibitors of von Willebrand factor binding to platelets. Blood 1993;81:1263-76.

22. Moake JL, Turner NA, Stathopoulos NA, Nolasco L, Hellums JD. Shear-induced platelet aggregation can be mediated by vWF released from platelets, as well as by exogenous large or unusually large vWF multimers, requires adenosine diphosphate, and is resistant to aspirin. Blood 1988;71:1366-74.

23. Phillips MD, Moake JL, Nolasco L, Turner N. Aurin tricarboxylic acid: a novel inhibitor of the association of von Willebrand factor and platelets. Blood 1988;72:1898-903.

24. Sixma JJ, Ijsseldijk MJ, Hindriks G, et al. Adhesion of blood platelets is inhibited by VCL, a recombinant fragment (leucine504 to lysine728) of von Willebrand factor. Arterioscler Thromb Vasc Biol 1996;16:64-71.

25. Acland RD, Anderson G, Siemionow M, McCabe S. Direct in vivo observations of embolic events in the microcirculation distal to a small-vessel anastomosis. Plast Reconstr Surg 1989;84:280-8.

26. Fujimoto T, Suzuki H, Tanoue K, Fukushima Y, Yamazaki H. Cerebrovascular injuries induced by activation of platelets in vivo. Stroke 1985;16:245-50.

\section{Bound volumes available to subscribers}

Bound volumes of The Journal of Thoracic and Cardiovascular Surgery are available to subscribers (only) for the 2000 issues from the Publisher, at a cost of $\$ 134.00$ for domestic, $\$ 165.85$ for Canadian, and $\$ 155.00$ for international subscribers for Vol 119 (January-June) and Vol 120 (July-December). Shipping charges are included. Each bound volume contains a subject and author index and all advertising is removed. Copies are shipped within 60 days after publication of the last issue of the volume. The binding is durable buckram with the Journal name, volume number, and year stamped in gold on the spine. Payment must accompany all orders. Contact Mosby, Subscription Customer Service, 6277 Sea Harbor Dr, Orlando, FL 32887,USA; phone 800-654-2452 or 407-345-4000.

Subscriptions must be in force to qualify. Bound volumes are not available in place of a regular Journal subscription. 